\section{Measuring motor complications in clinical trials for early Parkinson's disease}

\section{Marras, A E Lang}

\section{Standardisation is needed}

T he development of dyskinesias and motor fluctuations is a major concern related to dopaminergic treatment for Parkinson's disease. These motor complications are common, ${ }^{1}$ and can be a significant source of disability. ${ }^{23}$ Numerous clinical trials have been conducted to compare treatments for their ability to delay, prevent, or reduce the severity of motor complications. Measuring motor complications is challenging because of the number of potentially important aspects, including frequency, intensity, predictability, phenomenology, as well as the need to rely on a subject's understanding and awareness of these phenomena because they are transient, often under-recognised by the affected patient, and often cannot be observed directly by study personnel.

As shown in table 1, the proportion of subjects experiencing motor complications with initial levodopa therapy recorded by several recent randomised, controlled trials of initial treatment of Parkinson's disease varies considerably. ${ }^{4-13}$ For example, the proportion of subjects recorded as having dyskinesias at five years of follow up varies across studies from $5 \%$ to $41 \%$. All of these trials recruited patients from similar populations who received levodopa in doses adjusted according to their individual needs. We examine the methods of measuring motor complications used in these trials as a source of variability in the results, and consider the implications of this variability for the results of clinical trials in this area and for the interpretation of the literature.

Table 2 summarises the methods used to record motor complications in clinical trials of early treatment for Parkinson's disease in which the occurrence of motor complications was a primary outcome..$^{4-14}$ Potential sources of variability in the results of these studies are multiple, but can be broadly classified into variability resulting from differing thresholds for declaring end points and variability attibutable to unstandardised ascertainment methods within study protocols. It is also clear that patient related factors will influence the incidence of these complications, including age of onset, ${ }^{15}{ }^{16}$ severity of disease at start of treatment, ${ }^{17}$ sex, ${ }^{18}$ and even genetic factors such as recently defined dopamine receptor gene polymorphisms ${ }^{1920}$ or mutations in the parkin gene. ${ }^{21}$ We will concentrate our discussion here on methodological issues.

\section{DEFINING THE THRESHOLD FOR RECOGNISING MOTOR COMPLICATIONS IN CLINICAL STUDIES}

To declare end points as having occurred, studies have varied in the degree of persistence and severity of motor complications required. Motor complications may resolve at least temporarily with adjustment of medications or occasionally spontaneously, particularly early in their course. Therefore, some investigators have required that these events persist at more than one consecutive visit before declaring them to be present. ${ }^{61122}$ The most stringent criteria for consecutive observations imposed were those of Monstastruc et al, ${ }^{9}$ who required that each motor complication be recorded by an objective observation by the physician on the next two visits, each at one month intervals. Taking a different approach, Larsen et al required that the subject be experiencing end of dose deterioration while taking levodopa given at least every four hours, four times per day, on two consecutive visits. ${ }^{6}$ Most other studies accepted the patient's first report of such a complication, regardless of persistence. Requiring repeat confirmation of motor complications would almost certainly reduce the overall frequency of motor complications recorded. It is also possible that the sensitivity for detecting differences in the propensity of different treatment regimens to cause motor complications could be reduced, as clinically important but transient episodes of

Table 1 Frequency of motor complications in those receiving levodopa in trials of initial treatment for Parkinson's disease. Presented in order of increasing length of follow up

\begin{tabular}{|c|c|c|c|c|c|c|c|c|}
\hline Reference & Number & $\begin{array}{l}\text { Mean age } \\
\text { (y) }\end{array}$ & $\begin{array}{l}\text { Mean } \\
\text { duration } \\
\text { of PD (y) }\end{array}$ & $\begin{array}{l}\text { Previous levodopa } \\
\text { exposure }\end{array}$ & $\begin{array}{l}\text { Mean length } \\
\text { of follow up } \\
\text { (y) }\end{array}$ & $\begin{array}{l}\text { Mean } \\
\text { levodopa } \\
\text { daily dose } \\
\text { at end of } \\
\text { follow up } \\
\text { (mg) }\end{array}$ & $\begin{array}{l}\text { Percentage } \\
\text { with } \\
\text { dyskinesias }\end{array}$ & $\begin{array}{l}\text { Percentage } \\
\text { with } \\
\text { fluctuations }\end{array}$ \\
\hline $\begin{array}{l}\text { Parkinson Study Group, } \\
1996^{4}\end{array}$ & 170 & 61.8 & NS & None & 1.7 & 350 & 26 & 48 \\
\hline $\begin{array}{l}\text { Parkinson Study Group, } \\
2000^{5}\end{array}$ & 150 & 60.9 & 1.8 & $\begin{array}{l}30 \text { subjects, duration not } \\
\text { stated }\end{array}$ & 2 & 509 & 31 & 38 \\
\hline Larsen et al, $1997^{\circ}$ & 81 & 64.3 & 2.0 & 22 subjects, 2.7 months & 2.7 & 450 & NA & 27 \\
\hline Caraceni et al, $2001^{7}$ & 156 & 63.4 & 1.3 & 13 subjects, $<4$ months & 2.8 & NS & 27 & 30 \\
\hline Rinne et al, $1998^{8}$ & 204 & 62.6 & 2.0 & None & 3.7 & NS & 14 & 19 \\
\hline Montastruc et al, $1994^{9}$ & 29 & 62 & 2.7 & None & 4.9 & 569 & \multicolumn{2}{|c|}{$\begin{array}{l}90 \text { (combined dyskinesias } \\
\text { and fluctuations) }\end{array}$} \\
\hline Dupont et al, $1996^{10}$ & $\begin{array}{l}29 \text { (completed } 5 \\
\text { years) }\end{array}$ & 66 & 2.7 & None & 5 & 719 & 41 & 59 \\
\hline Koller et al, $1999^{11}$ & $\begin{array}{l}187 \text { (completed } 5 \\
\text { years) }\end{array}$ & 62 & 2.3 & None & 5 & 426 & 8 & $25^{*}$ by diary \\
\hline Rascol et al, $2000^{12}$ & $\begin{array}{l}89 \text { (completed } 5 \\
\text { years) }\end{array}$ & 63 & 2.4 & 7 subjects, $<6$ weeks & 5 & 753 & 40 & 34 \\
\hline Lees et al, $1995^{13}$ & 249 & 62.7 & 1.1 & None & 5.5 & $\begin{array}{l}625 \text { at } 4 \\
\text { years }\end{array}$ & 32 & 43 \\
\hline
\end{tabular}

PD, Parkinson's disease; NS, not stated; NA, not assessed. *Estimated from figure in paper. 
Table 2 Methods of measuring motor complications in clinical trials of early treatment of Parkinson's disease

\begin{tabular}{|c|c|c|c|c|c|c|c|c|}
\hline Reference & Treatments compared & Self report adequate & $\begin{array}{l}\text { Requiring } \\
\text { repeat } \\
\text { confirmation }\end{array}$ & Other requirements & $\begin{array}{l}\text { Teaching } \\
\text { method } \\
\text { used }\end{array}$ & $\begin{array}{l}\text { Severity } \\
\text { reported }\end{array}$ & $\begin{array}{l}\text { Frequency } \\
\text { reported }\end{array}$ & $\begin{array}{l}\text { Existing } \\
\text { scale used }\end{array}$ \\
\hline $\begin{array}{l}\text { Cedarbaum, } \\
1991^{14}\end{array}$ & $\begin{array}{l}\text { Early vs delayed } \\
\text { initiation of L-dopa }\end{array}$ & Yes & No & None & NS & No & No & No \\
\hline $\begin{array}{l}\text { Montastruc, } \\
1994^{9}\end{array}$ & $\begin{array}{l}\text { bromocriptine } v \\
\text { levodopa }\end{array}$ & Yes & Yes, $\times 2$ & None & NS & No & No & No \\
\hline Lees, $1995^{13}$ & $\begin{array}{l}\text { L-dopa+selegiline } v \\
\text { L-dopa }\end{array}$ & NS & NS & None & NS & Yes & No & No* \\
\hline \multirow[t]{2}{*}{ PSG, $1996^{4}$} & \multirow{2}{*}{$\begin{array}{l}\text { Selegiline then L-dopa } v \\
\text { L-dopa }\end{array}$} & Fluctuations: Yes & No & None & No & No & No & No \\
\hline & & Dyskinesias: No & No & None & No & No & No & No \\
\hline Dupont, $1996^{10}$ & $\begin{array}{l}\text { Madopar HBS v } \\
\text { standard Madopar }\end{array}$ & Yes & NS & None & NS & Yes & Yes & $\begin{array}{l}\text { Yes } \\
\text { (UPDRS IV) }\end{array}$ \\
\hline Larsen, $1997^{\circ}$ & $\begin{array}{l}\text { L-dopa+selegiline } v \\
\text { L-dopa }\end{array}$ & NS & Yes, $\times 1$ & $\begin{array}{l}\text { Motor fluctuations on } \\
\text { qid L-dopa given } q 4 \mathrm{~h}\end{array}$ & NS & No & No & No \\
\hline Rinne, $1998^{8}$ & Cabergoline $v$ L-dopa & NS & Yes, $\times 1$ & None & NS & Yes & No & No \\
\hline \multirow[t]{2}{*}{ Koller, $1999^{11}$} & \multirow[t]{2}{*}{$\begin{array}{l}\text { Sinemet CR v regular } \\
\text { Sinemet }\end{array}$} & Yes (patient diary) & Yes, $\times 1$ & $\begin{array}{l}\text { Dyskinesia }>10 \% \text { of } \\
\text { waking day or "Off" } \\
\text { greater than } 20 \% \text { of } \\
\text { waking day by patient } \\
\text { diary }\end{array}$ & NS & No & Yes & No \\
\hline & & $\begin{array}{l}\text { Yes (examiner } \\
\text { administered } \\
\text { questionnaire) }\end{array}$ & Yes, $\times 1$ & $\begin{array}{l}5 \text { of } 10 \text { questions on } \\
\text { the examiner } \\
\text { administered } \\
\text { questionnaire } \\
\text { answered affirmative }\end{array}$ & NS & No & Yes & Not \\
\hline Rascol, $2000^{12}$ & Ropinirole $v$ L-dopa & Yes & No & None & No & Yes & No & $\begin{array}{l}\text { Yes } \\
\text { (UPDRS IV) }\end{array}$ \\
\hline PSG, $2000^{5}$ & Pramipexole $v$ L-dopa & Yes & No & None & NS & No & No & No \\
\hline $\begin{array}{l}\text { Caraceni, } \\
2001^{7}\end{array}$ & $\begin{array}{l}\text { L-dopa, lisuride, } \\
\text { bromocriptine, selegiline }\end{array}$ & NS & NS & None & NS & No & No & No \\
\hline
\end{tabular}

motor complications may not be recorded.

As mild motor complications may not even be noticed by the patient, it follows that some complications are clinically important and others are not. Most studies have concentrated on recording the first detected occurrence of motor complications as end points, and have not incorporated a threshold of severity into criteria for determining end point status. Attempting to record only clinically relevant dyskinesias and fluctuations, Koller et al ${ }^{11}$ (The CR First study) required that dyskinesias be present at least $10 \%$ of the waking day, and off periods be present $20 \%$ of the day. These criteria had to apply on two consecutive visits between which changes in drug dose or timing were permitted.

Considering both requirements of severity and persistence together, the criteria used to define end points in clinical trials of motor complications represent a broad range of thresholds for declaring whether or not a motor complication has occurred. The criteria vary from accepting dyskinesias or motor fluctuations regardless of their level of severity on the first report by the subject ${ }^{451214}$ to requiring a minimum percentage of the day spent in the off state or with dyskinesias at more than one consecutive visit. ${ }^{11}$ As shown in table 1, the study applying the more stringent criteria (that is, Koller et $a l^{11}$ ) recorded a particularly low incidence of dyskinesias and fluctuations at five years of follow up. Each approach may have its own advantages. Low thresholds for motor complication end points may provide more sensitive measures of the time of first occurrence, and may detect subtle differences between treatment strategies (which could provide important clues to the pathophysiology of dyskinesias and fluctuations) that more stringent thresholds would miss. Setting higher thresholds, however, may provide a more clinically relevant comparison between treatment strategies by excluding mild, transient, or easily managed motor complications that are not bothersome to patients. Combining the two approaches in any one trial could provide a more comprehensive picture of the evolution of motor complications on different treatment regimens.

Although most recent clinical trials comparing treatment strategies have compared treatments for their ability to delay the onset of motor complications, it is unknown whether or not the timing of first occurrence alone is an important outcome. Delaying the first occurrence of motor complications has not yet been demonstrated to result in later benefit in either function or quality of life. Neither has it been demonstrated how patients value the first onset of these symptoms. ${ }^{23}$ Therefore, it is important that evaluations of the clinical impact of motor complications be carried out longitudinally. This viewpoint was put forth in a Dyskinesia Assessment Workshop in $1999 .^{24}$ A measure of overall disability has been used in most trials; less commonly measures of health related quality of life have been incorporated. ${ }^{511}$

A minority of studies have combined a low detection threshold with a specific assessment of the severity of motor complications. The Unified Parkinson's Disease Rating Scale (UPDRS) motor complication subscale (IV) has been used in a few studies, ${ }^{10}{ }^{12}$ and one study rated both dyskinesia and motor fluctuation severity on separate four point scales. ${ }^{13} \mathrm{Nu}$ merous scales exist for the rating of dyskinesia severity. ${ }^{25}$ Several of these scales have incorporated measurements of function as well as dyskinesia frequency and phenomenology to capture the impact of the motor complication on the patient. These scales have been primarily used in studies evaluating treatment impact on established dyskinesias. ${ }^{26-29}$ The use of such scales in early treatment studies would serve to provide insight into the importance of any differences in motor complication timing or frequency that is demonstrated. However, the variability in dyskinesias, particularly early in the course of Parkinson's disease must also be considered. For example, dyskinesias may initially be present only in stressful circumstances or only later in the day. Timing and duration of motor complications are additional factors that influence their impact on patients, and should be incorporated into assessments of motor complications in early disease. 


\section{STANDARDISATION OF ASCERTAINMENT METHODS}

A second source of variability in the measurement of motor complications is unstandardised ascertainment methods. The questioning used to elicit information from study subjects regarding the occurrence of motor fluctuations is generally permitted to vary between research personnel. This is a particular concern for dyskinesias, as patients often do not recognise their occurrence, ${ }^{30}$ and may also mistake tremor for dyskinesias. Thus, unstandardised questioning of subjects leaves open the possibility of varying degrees of under or overascertainment. Such variability within a study has the potential to introduce "noise" into measurement sufficient to obscure clinically important differences between groups. In addition, unstandardised measurement leaves results more susceptible to measurement bias, as the assessment of the occurrence of complications can be more easily influenced (consciously or subconsciously) by the investigator's impression of which treatment is being received.

The CR First study (Koller $e t a^{11}$ ) is an exception in that the investigators applied two distinct and standardised methods of questioning for the occurrence of motor complications: a patient diary and examiner administered questionnaire. This study also confirmed how variation in standardised methods of ascertainment can influence motor complication frequency; the combined frequency of dyskinesias and fluctuations in the immediate release levodopa/ carbidopa arm was found to be $21 \%$ at five years of treatment using the patient diary recording method but only 16\% using the questionnaire definition.

The difficulty that patients have recognising mild motor complications presents a challenge to investigators who must rely on patient self report to identify the time of first occurrence of these episodic phenomena. It has been demonstrated in patients with more advanced disease that using an instructional videotape can considerably improve the agreement between trained professionals and patients on the occurrence of motor fluctuations. ${ }^{31}$ The use of such a videotape is not usual, even though maximising the precision of this assessment would improve the efficiency of studies comparing two treatment strategies. The concern has been raised that the use of such training strategies in early patients who have not yet experienced these problems may encourage excessive fixation on the occurrence of dyskinesias, which could generate unneeded stress for the subjects and their families. ${ }^{24}$ However, with appropriate counselling standardised instruction could become an important adjunct to the measurement methods.

\section{IMPLICATIONS FOR INTERPRETING THE LITERATURE}

The most obvious implication of variability in methods of recording motor complications for interpreting the literature is that we must exercise caution when comparing results across studies. As there are no direct comparisons of the newer dopamine agonists, it is tempting to compare them across studies with respect to their propensity to cause motor complications. While the study designs are superficially similar, comparison with respect to their primary end points is unlikely to yield meaningful results. Caution should also be exercised when using the results of a trial with very rigorous criteria for the diagnosis of motor complications (for example, Koller $\left.e t ~ a l^{11}\right)$ to reassure readers of the low risk of these complications.

The frequency of levodopa induced motor complications has been estimated by combining the results of existing studies. ${ }^{1}$ Such information is valuable for guiding future research, for example to aid sample size planning for clinical trials, and for estimating the potential impact of treatments aimed at reducing these complications. However, variability in the definitions and methods of ascertaining motor complications significantly increases the uncertainty surrounding the estimates derived from meta-analyses, and also calls into question the usefulness of combining results. Although some differences between studies are unavoidable, studies that clearly measure a different spectrum of severity of motor complications should be kept distinct, and frequencies of motor complications reported should be interpreted with an understanding of the thresholds used to define these phenomena.

In summary, there are multiple sources of variability in the methods of measuring motor complications, including differences in the threshold for recognising them and unstandardised methods of questioning research subjects. These factors probably contribute to the differences in the rates of motor complications reported to date, and may compromise our ability to detect the true magnitude of difference between treatment strategies and to compare across studies. An approach of standardised questioning to detect the first occurrence of motor complications, complemented by suitable instruction to ensure optimal patient recognition of dyskinesias and motor fluctuations would optimise early, accurate detection. In combination with ongoing assessment of the severity and impact of motor complications, the clinical relevance of any differences in frequency of motor complications may be assessed. This is particularly important now, when the occurrence of dyskinesias and fluctuations is becoming a major factor in the comparison of treatment strategies in early Parkinson's disease.

J Neurol Neurosurg Psychiatry
2003;74:143-146

\section{Authors' affiliations}

C Marras, A E Lang, Division of Neurology, Toronto Western Hospital, University Health Network and University of Toronto, Canada

Correspondence to: Dr A E Lang, Morton and Gloria Shulman Movement Disorders Centre, Toronto Western Hospital, $11-M P, 399$ Bathurs Street, Toronto, Ontario M5G 2S8, Canada; lang@uhnres.utoronto.ca

\section{REFERENCES}

1 Ahlskog JE, Muenter MD. Frequency of levodopa-related dyskinesias and motor fluctuations as estimated from the cumulative literature. Mov Disord 2001; 16:448-58.

2 Damiano AM, McGrath MM, Willian MK, et al. Evaluation of a measurement strategy for Parkinson's disease: assessing patient health-related quality of life. Qual Life Res 2000;9:87-100

3 Pechevis $M$, Clarke CE, Vieregge $P$, et al. Direct and indirect costs of Parkinson's disease and l-dopa-induced dyskinesia: a Prospective European Study. Parkinsonism and Related Disorders 2001;7:S106

4 Parkinson Study Group. Impact of deprenyl and tocopherol treatment on Parkinson's disease in DATATOP patients requiring levodopa. Ann Neurol 1996;39:37-45.

5 Parkinson Study Group. Pramipexole vs levodopa as initial treatment for Parkinson disease: A randomized controlled trial. JAMA 2000;284:1931-8

6 Larsen JP, Boas J. The effects of early selegiline therapy on long-term levodopa treatment and parkinsonian disability: an interim analysis of a Norwegian-Danish 5-year study. Norwegian-Danish Study Group. Mov Disord 1997;1 2:175-82.

7 Caraceni T, Musicco M. Levodopa or dopamine agonists, or deprenyl as initial treatment for Parkinson's disease. A randomized multicenter study. Parkinsonism and Related Disorders 2001;7:107-14.

8 The PKDS009 Study Group. Early treatment of Parkinson's disease with cabergoline delays the onset of motor complications. Results of a double-blind levodopa controlled trial. Drugs 1998;55:23-30.

9 Montastruc JL, Rascol O, Senard JM, et al. A randomised controlled study comparing bromocriptine to which levodopa was later added, with levodopa alone in previously untreated patients with Parkinson's disease: a five year follow up. J Neurol Neurosurg Psychiatry 1994;57:1034-8.

10 Dupont E, Andersen A, Boas J, et al. Sustained-release Madopar HBS compared with standard Madopar in the long-term treatment of de novo parkinsonian patients. Acta Neurol Scand 1996;93:14-20

11 Koller WC, Hutton JT, Tolosa E, et al. Immediate-release and controlled-release carbidopa/levodopa in PD: a 5-year randomized multicenter study. Carbidopa/Levodopa Study Group. Neurology 1999;53:1012-19.

12 Rascol O, Brooks DJ, Korczyn AD, et al. A five-year study of the incidence of dyskinesia in patients with early Parkinson's disease who were treated with ropinirole or levodopa. 056 Study Group. N Engl J Med 2000:342:1484-91.

13 Lees AJ, For the Parkinson's Disease Research Group of the United Kingdom. Comparison of therapeutic effects and mortality data of levodopa and levodopa combined with selegiline in patients with early, mild Parkinson's disease. BM 1995;311:1602-7. 
14 Cedarbaum JM, Gandy SE, McDowell FH. "Early" initiation of levodopa treatment does not promote the development of motor response fluctuations, dyskinesias, or dementia in Parkinson's disease. Neurology 1991;41:622-9.

15 Wu RM, Chiu HC, Wang M, et al. Risk factors on the occurrence of response fluctuations and dyskinesias in Parkinson's disease. J Neural Transm Park Dis Dement Sect 1993;5:127-33

16 Kostic V, Przedborski S, Flaster E, et al. Early development of levodopa-induced dyskinesias and response fluctuations in young-onset Parkinson's disease. Neurology 1991:41:202-5.

17 de Jong GJ, Meerwaldt JD, Schmitz PIM Factors that influence the occurrence of response variations in Parkinson's disease. Ann Neurol 1987;22:4-7.

18 Hely MA, Morris JG, Reid WG, et al. Age at onset: the major determinant of outcome in Parkinson's disease. Acta Neurol Scand 1995;92:455-63.

19 Oliveri RL, Annesi G, Zappia M, et al Dopamine D2 receptor gene polymorphism and the risk of levodopa-induced dyskinesias in PD. Neurology 1999;53:1425-30.

20 Wang J, Liu ZL, Chen B. Association study of dopamine D2, D3 receptor gene polymorphisms with motor fluctuations in PD. Neurology 2001;56:1757-9.

21 Bonifati V, De Michele G, Lucking CB, et al. The parkin gene and its phenotype. Italian PD Genetics Study Group, French PD Genetics Study Group and the European Consortium on Genetic Susceptibility in Parkinson's Disease. Neurol Sci 2001;22:51-2.

22 Rinne U, Bracco F, Chouza C, et al. Early treatment of Parkinson's disease with cabergoline delays the onset of motor complications. Results of a double-blind levodopa controlled trial. Drugs 1998;55:23-30.

23 Holloway RG, Dick AW. Clinical trial endpoints: On the road to nowhere? Neurology 2002;58:679-86.

24 Melamed E, Olanow CW, Nutt JG, et al. Dyskinesias assessment workshop: reports from the working groups. Mov Disord 1999; 14:69-73.
25 Goetz CG. Rating scales for dyskinesias in Parkinson's disease. Mov Disord 1999; 14:48-53.

26 Sieradzan KA, Fox SH, Hill M, et al Cannabinoids reduce levodopa-induced dyskinesia in Parkinson's disease: a pilot study. Neurology 2001;57:2108-11.

27 Manson AJ, Schrag A, Lees AJ. Low-dose olanzapine for levodopa induced dyskinesias. Neurology 2000;55:795-9.

28 Parkinson Study Group. Evaluation of dyskinesias in a pilot, randomized placebo-controlled trial of remacemide in advanced Parkinson disease. Arch Neurol 2001;58: 1660-8

29 Krause M, Fogel W, Heck A, et al. Deep brain stimulation for the treatment of Parkinson's disease: subthalamic nucleus versus globus pallidus internus. J Neurol Neurosurg Psychiatry 2001;70:464-70.

30 Golbe LI, Pae J. Validity of a mailed epidemiological questionnaire and physical self-assessment in Parkinson's disease. Mov Disord 1988;3:245-54.

31 Goetz CG, Stebbins GT, Blasucci LM, et al. Efficacy of a patient-training videotape on motor fluctuations for on- off diaries in

Parkinson's disease. Mov Disord 1997;12:1039-41. 